\title{
Sensitivity study of surface wind flow of a limited area model simulating the extratropical storm Delta affecting the Canary Islands
}

\author{
C. Marrero ${ }^{1}$, O. Jorba ${ }^{2}$, E. Cuevas ${ }^{1}$, and J. M. Baldasano ${ }^{2,3}$ \\ ${ }^{1}$ Izaña Atmospheric Research Center, Meteorological State Agency of Spain (AEMET), Tenerife, Spain \\ ${ }^{2}$ Earth Sciences Department, Barcelona Supercomputing Center - Centro Nacional de Supercomputación, \\ Barcelona, Spain \\ ${ }^{3}$ Environmental Modelling Laboratory, Technical University of Catalonia, Barcelona, Spain
}

Received: 21 December 2008 - Revised: 1 February 2009 - Accepted: 10 April 2009 - Published: 27 April 2009

\begin{abstract}
In November 2005 an extratropical storm named Delta affected the Canary Islands (Spain). The high sustained wind and intense gusts experienced caused significant damage. A numerical sensitivity study of Delta was conducted using the Weather Research \& Forecasting Model (WRF-ARW). A total of 27 simulations were performed. Non-hydrostatic and hydrostatic experiments were designed taking into account physical parameterizations and geometrical factors (size and position of the outer domain, definition or not of nested grids, horizontal resolution and number of vertical levels). The Factor Separation Method was applied in order to identify the major model sensitivity parameters under this unusual meteorological situation. Results associated to percentage changes relatives to a control run simulation demonstrated that boundary layer and surface layer schemes, horizontal resolutions, hydrostaticity option and nesting grid activation were the model configuration parameters with the greatest impact on the $48 \mathrm{~h}$ maximum $10 \mathrm{~m}$ horizontal wind speed solution.
\end{abstract}

\section{Introduction}

On 28-29 November 2005 an extratropical storm affected the Canary Islands (Spain) causing significant damage related to high sustained wind and intense gusts (Table 1) over some islands of the archipelago (Fig. 1). The extratropical storm named Delta was characterized by a warm core around $850 \mathrm{hPa}$ (Beven, 2006; Martín et al., 2006). It represented an unusual meteorological phenomena for that region, and its impacts were underestimated by the different operational meteorological forecasts (Martín et al., 2006). Highly non linear interaction of the flow with the islands complex topography, due to the existence of the warm core at the mountain top level, was the main factor that produced gusts over $160 \mathrm{~km} / \mathrm{h}$ at La Palma, $90 \mathrm{~km} / \mathrm{h}$ on the coast in Tenerife, and over $215 \mathrm{~km} / \mathrm{h}$ in its mountain top with the development of strong downslope winds (Jorba et al., 2007; Marrero et al., 2007). Further details can be found in (Jorba et al., 2008).

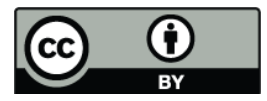

Correspondence to: C. Marrero (cmarrero@inm.es)
Several authors have analyzed the sensitivity of numerical weather prediction models under extratropical storm situations, taking into account the impact of the observing system and the initial conditions (Zou et al., 1998; Zhu and Thorpe, 2006; Froude et al., 2007) and the model uncertainties such as numerical scheme, horizontal and vertical resolution and physical parameterizations (Orlanski et al., 1991; Prater and Evans, 2002; Forbes and Clark, 2003; Jung et al., 2006). They have found a clear dependence on the predictability of extratropical cyclones with the initial condition and model configuration. The main objective of the present work aims to analyze the sensitivity of the Weather Research \& Forecasting Model (WRF-ARW v2.1.2 \& WRF Standard Initialization preprocessor) (Michalakes et al., 2004; Skamarock et al., 2005) modelling the extratropical storm Delta (NHC, 2006) in its fast evolving extratropical transition phase in reference with the surface wind field. We have designed 27 configurations of WRF-ARW to take into account modifications in domain dimension and location, horizontal resolution, number of vertical levels and physical parameterizations. These permitted us to survey their impact on the 10 $\mathrm{m}$ horizontal wind field. The factor separation method (Stein and Alpert, 1993; Alpert et al., 1995b) was used to quantify 
Table 1. $10 \mathrm{~m}$ maximum wind speed (MWS10m) and gusts (GS10m) measured by the principal meteorological stations located in the Canary Islands.

\begin{tabular}{llll}
\hline Station name & $\begin{array}{l}\text { MWS10m } \\
\mathrm{km} / \mathrm{h}\end{array}$ & $\begin{array}{l}\text { GS10m } \\
\mathrm{km} / \mathrm{h}\end{array}$ & $\begin{array}{l}\text { Time UTC } \\
\text { 28 Nov 2005 }\end{array}$ \\
\hline Hierro airport & 67 & 118 & $18: 00$ \\
Tazacorte & 31 & 59 & $12: 30$ \\
La Palma airport & 104 & 166 & $19: 00$ \\
La Gomera & 48 & 92 & $16: 00$ \\
Tenerife North airport & 30 & 70 & $16: 00$ \\
S/C de Tenerife & 57 & 132 & $21: 00$ \\
Tenerife South airport & 87 & 134 & $21: 40$ \\
Izaña & 180 & 218 & $20: 00$ \\
\hline
\end{tabular}

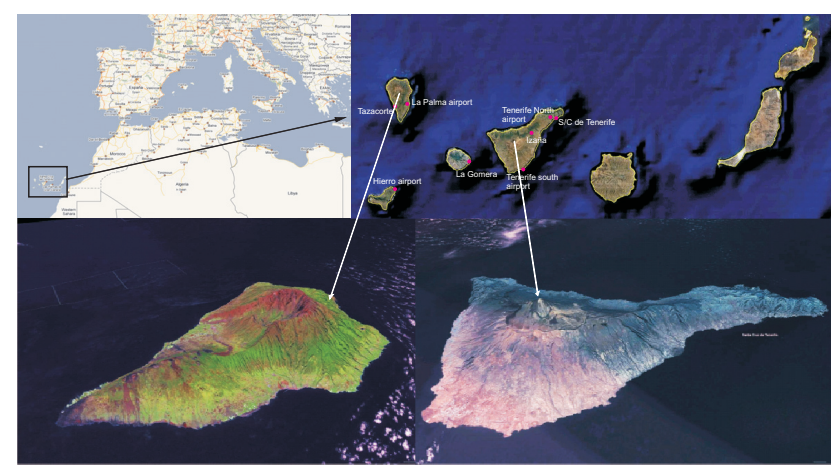

Figure 1. Location of the Canary Islands and the observation points. Tenerife and La Palma are the islands of the archipelago with the steepest orography and were the most affected by Delta.

in detail the effect of the variation of these parameters on the simulated $10 \mathrm{~m}$ horizontal wind speed. It is a consistent approach for calculating the contributions of various physical processes, as well as their mutual interactions. The method has been widely used by several authors; for example, see Alpert and Tsidulko (1994), Alpert et al. (1995a), Alpert et al. (1996a), Alpert et al. (1996b), Berger (2001), Darby et al. (2002), Guan and Reuter (1996), Lynn et al. (2001), Ramis and Romero (1995) and Romero et al. (1997).

\section{Methods}

\subsection{Model setup}

To explore the impact of the model configuration in the wind flow numerical solution we have designed several nonhydrostatic and hydrostatic experiments taking into account physical parameterizations and geometrical factors (size and position of the outer domain, definition or not of nested grids, horizontal resolution and number of vertical levels).

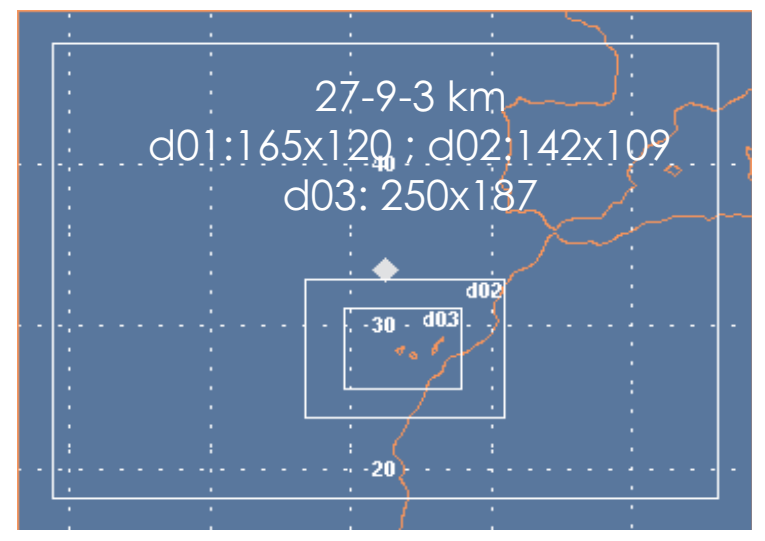

Figure 2. Domain configuration of the Control Run Experiment designed using the wrfsi preprocessor. The horizontal grid resolutions are 27, 9 and $3 \mathrm{~km}$, with a 31 vertical levels WRF-ETA distribution. Associated physics are: WSM microphysics, MO-YSU surface layer and boundary layer, and KF cumulus parameterization.

Twelve combinations of physical schemes (Skamarock et al., 2005) were obtained using 3 microphysics (MP) schemes: Lin scheme (LIN), WSM 3-class simple ice (WSM) and Ferrier microphysics (FER); 2 surface-boundary layer schemes (SL\&BL): Monin-Obukhov (MM5 similarity) \& YSU (MO-YSU) and Monin-Obukhov (Janjic Eta) \& Mellor-Yamada-Janjic (Eta) TKE (MOJ-MYJ); 2 cumulus options (CU): Kain-Fritsch (KF) and Betts-Miller-Janjic (BMJ).

Lateral boundary conditions (LBC) are known to provide a basic limitation to the predictability of local area models (Warner et al., 1997). Several errors produced on LBC specification are mainly propagated into the domain at nearadvective speeds by the mean flow, so in order to minimize these effects in our interest area, the mother domain has been dimensioned considering HYSPLIT (Draxler and Rolph, 2003) backward trajectories results (not shown) with the destination centered in the Canary Islands $\left(28^{\circ} \mathrm{N} 16^{\circ} \mathrm{W}\right)$ at several levels $(0.5,1,2,3,4,5,6,8$ and $10 \mathrm{~km})$ in the $48 \mathrm{~h}$ model simulation run.

The Control Run Experiment (CRE) domain, with twoway nesting grids of resolution 27, 9 and $3 \mathrm{~km}$ (Fig. 2) and a 31 sigma (WRF-Eta) levels configuration scheme (McCaslin et al., 2004), has been designed in order to optimize computational costs (most of the simulations were run with this domain configuration). The associated physical combination of the CRE was: WSM microphysics, MO-YSU surface layer and boundary layer and KF cumulus parameterization.

The 31 sigma levels distribution was interpolated applying a cubic spline scheme to obtain the 41 and 61 level arrangements. Two cases were run considering variations of the CRE with these level schemes. Other experiments were built positioning the mother domain $10^{\circ} \mathrm{S}, 10^{\circ} \mathrm{E}$ and $10^{\circ} \mathrm{W}$ in relation to the centered case and reducing it by $25 \%$ and $50 \%$. 


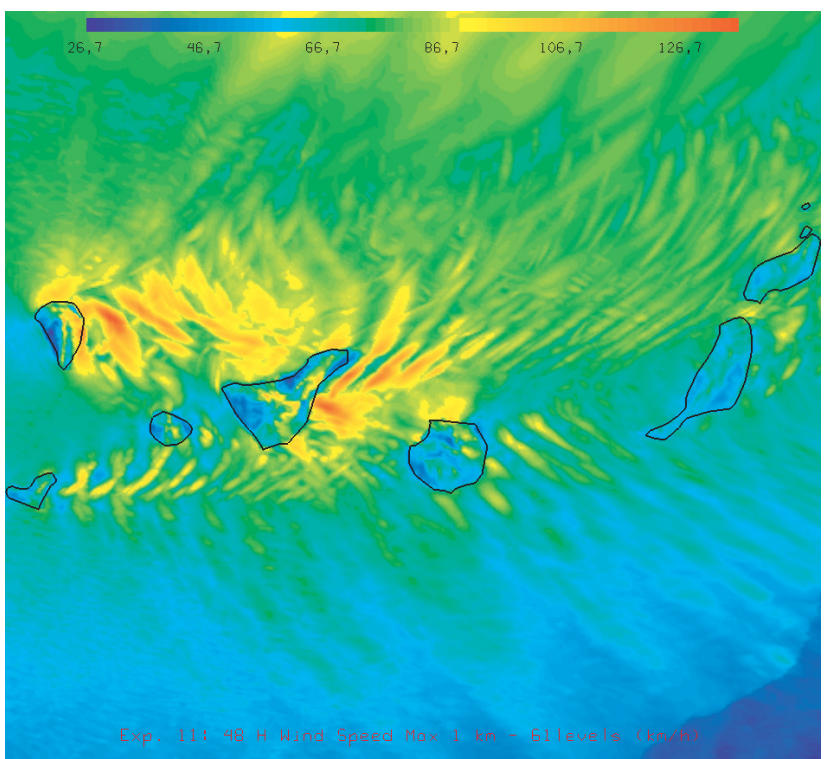

Figure 3. Maximum $10 \mathrm{~m}$ horizontal wind speed $(f)$ in $\mathrm{km} / \mathrm{h}$ for the $48 \mathrm{~h}$ run, results shown for experiment 11 (see Table 3 ).

Non-nested domain cases were defined with resolutions of 2, 3, 6, 9 and $27 \mathrm{~km}$. Two other experiments using 31 vertical levels with two-way nesting grids of horizontal resolutions of 18,6 , and $2 \mathrm{~km}$, and 61 levels with resolutions of $27,9,3$, and $1 \mathrm{~km}$ were conducted. The last experiment was run using 27 , 9 and $3 \mathrm{~km}$ two-way nesting grids with the hydrostatic option activated. A total of 27 experiments formed a cluster available to explore the variability of the numerical solution. All simulations used the $0.25^{\circ}$ reanalysis of the European Center for Medium Range Weather Forecasting (ECMWF) as initial and boundary conditions every six hours. Comparisons of the model simulations with surface observations have been presented in previous work (Jorba et al., 2007, 2008; Marrero et al., 2007).

\subsection{Factor separation methodology}

To quantify the impact on the $10 \mathrm{~m}$ wind solution due to different configurations of the WRF-ARW model, we have used the factor separation technique formulated by Stein and Alpert (1993), following the methodology adopted by Jankov et al. (2005). Based on this methodology the contribution of each factor can be quantified by:

$\hat{f}_{x}=f_{x}-f_{0}$

$\hat{f_{y}}=f_{y}-f_{0}$

$\hat{f}_{x y}=f_{x y}-\left(f_{x}+f_{y}\right)+f_{0}$

where $f_{0}$ represents the CRE output for the chosen variable (in our case the maximum grid point $10 \mathrm{~m}$ horizontal wind
Table 2. Configuration parameter options defined in the 27 experiments.

\begin{tabular}{ll}
\hline Configuration parameter & Notation \\
\hline Microphysics options & MP \\
Lin. scheme & LIN \\
WSM 3-class simple ice & WSM \\
Ferrier microphysics & FER \\
& \\
Surface-Layer \& Boundary-Layer Options & SL\&BL \\
Monin-Obukhov \& YSU Scheme & MO-YSU \\
Monin-Obukhov (Janjic Eta) \& & MOJ-MYJ \\
Mellor-Yamada-Janjic (Eta) TKE & \\
& \\
Cumulus options & CU \\
Kain-Fritsch & KF \\
Betts-Miller-Janjic & BMJ \\
Inner grid resolution & \\
& GR \\
Nesting two-way activation & $27,9,6,3,2$ \\
Number of WRF-ETA scheme vertical levels & NL 1 km \\
Percentage of mother grid reduction & NA \\
Position of mother grid & PGR or 61 \\
& $25 \%$ or $50 \%$ \\
& PMG \\
& Centered, 10E, \\
& $10 W$ or $10 \mathrm{~S}$ \\
& HY \\
& Yes or No \\
\hline & \\
& \\
&
\end{tabular}

speed in the $48 \mathrm{~h}$ run (Fig. 3)), $f_{x}$ represents the maximum $10 \mathrm{~m}$ wind speed produced by a run that has one of the configuration parameters of the model changed, $f_{y}$ the maximum wind speed obtained when another parameter is changed and $f_{x y}$ obtained when the two parameters are changed simultaneously. $\hat{f}_{x y}$ stands for a synergistic term reflecting the nonlinear interaction between the two different configuration parameters. Notation presented in Table 2 will be used to identify the different model configurations used with this methodology.

\section{Results}

A total of 24 configurations have been compared against the CRE (synergism among three different processes were not considered), with italic and bold letters in Table 3 identifying the options that were varied. Nonlinear interactions were calculated in cases 5, 6, 7, 8 and 9. In experiments 11, 20, 22,23 and 24 only the factor $f_{x y}$ was determined. Percentage changes for every grid point were plotted in order to measure 
Table 3. Configuration details of experiments compared against the Control Run Experiment (CRE). Italic and bold letters indicate the parameters (notation defined in Table 2) that have been varied in each experiment.

\begin{tabular}{|c|c|c|c|c|c|c|c|c|c|}
\hline Experiment & $\begin{array}{c}\text { Configuration Parameter } \\
\text { MP }\end{array}$ & SL\&BL & $\mathrm{CU}$ & GR & NA & NL & PGR & PMG & HY \\
\hline CRE & WSM & MO-YSU & $\mathrm{KF}$ & 3 & Y & 31 & 0 & $\mathrm{C}$ & $\mathrm{N}$ \\
\hline EXP.1 & WSM & MO-YSU & $B M J$ & 3 & Y & 31 & 0 & $\mathrm{C}$ & $\mathrm{N}$ \\
\hline EXP. 2 & WSM & MOJ-MYJ & $\mathrm{KF}$ & 3 & Y & 31 & 0 & $\mathrm{C}$ & $\mathrm{N}$ \\
\hline EXP.3 & $L I N$ & MO-YSU & KF & 3 & Y & 31 & 0 & $\mathrm{C}$ & $\mathrm{N}$ \\
\hline EXP.4 & FER & MO-YSU & $\mathrm{KF}$ & 3 & Y & 31 & 0 & $\mathrm{C}$ & $\mathrm{N}$ \\
\hline EXP.5 & WSM & MOJ-MYJ & $B M J$ & 3 & Y & 31 & 0 & $\mathrm{C}$ & $\mathrm{N}$ \\
\hline EXP.6 & $L I N$ & MOJ-MYJ & $\mathrm{KF}$ & 3 & Y & 31 & 0 & $\mathrm{C}$ & $\mathrm{N}$ \\
\hline EXP.7 & FER & MOJ-MYJ & $\mathrm{KF}$ & 3 & Y & 31 & 0 & $\mathrm{C}$ & $\mathrm{N}$ \\
\hline EXP.8 & $L I N$ & MO-YSU & $B M J$ & 3 & Y & 31 & 0 & $\mathrm{C}$ & $\mathrm{N}$ \\
\hline EXP.9 & $F E R$ & MO-YSU & $B M J$ & 3 & Y & 31 & 0 & $\mathrm{C}$ & $\mathrm{N}$ \\
\hline EXP.10 & WSM & MO-YSU & $\mathrm{KF}$ & 2 & Y & 31 & 0 & $\mathrm{C}$ & $\mathrm{N}$ \\
\hline EXP.11 & WSM & MO-YSU & KF & 1 & Y & 61 & 0 & $\mathrm{C}$ & $\mathrm{N}$ \\
\hline EXP.12 & WSM & MO-YSU & KF & 3 & Y & 41 & 0 & $\mathrm{C}$ & $\mathrm{N}$ \\
\hline EXP.13 & WSM & MO-YSU & KF & 3 & Y & 61 & 0 & $\mathrm{C}$ & $\mathrm{N}$ \\
\hline EXP.14 & WSM & MO-YSU & KF & 3 & Y & 31 & 25 & $\mathrm{C}$ & $\mathrm{N}$ \\
\hline EXP.15 & WSM & MO-YSU & KF & 3 & $\mathrm{Y}$ & 31 & 50 & $\mathrm{C}$ & $\mathrm{N}$ \\
\hline EXP.16 & WSM & MO-YSU & KF & 3 & $\mathrm{Y}$ & 31 & 0 & $E$ & $\mathrm{~N}$ \\
\hline EXP.17 & WSM & MO-YSU & $\mathrm{KF}$ & 3 & Y & 31 & 0 & $W$ & $\mathrm{~N}$ \\
\hline EXP.18 & WSM & MO-YSU & KF & 3 & Y & 31 & 0 & $S$ & $\mathrm{~N}$ \\
\hline EXP.19 & WSM & MO-YSU & KF & 3 & Y & 31 & 0 & $\mathrm{C}$ & $Y$ \\
\hline EXP.20 & WSM & MO-YSU & KF & 2 & $N$ & 31 & 0 & $\mathrm{C}$ & $\mathrm{N}$ \\
\hline EXP.21 & WSM & MO-YSU & $\mathrm{KF}$ & 3 & $N$ & 31 & 0 & $\mathrm{C}$ & $\mathrm{N}$ \\
\hline EXP. 22 & WSM & MO-YSU & $\mathrm{KF}$ & 6 & $N$ & 31 & 0 & $\mathrm{C}$ & $\mathrm{N}$ \\
\hline EXP.23 & WSM & MO-YSU & $\mathrm{KF}$ & 9 & $N$ & 31 & 0 & $\mathrm{C}$ & $\mathrm{N}$ \\
\hline EXP.24 & WSM & MO-YSU & KF & 27 & $N$ & 31 & 0 & $\mathrm{C}$ & $\mathrm{N}$ \\
\hline
\end{tabular}

the magnitude of the variation in a common domain of $3 \mathrm{~km}$ resolution. This percentage change was calculated as

$\frac{\hat{f}_{x}}{f_{0}} x 100, \quad \frac{\hat{f}_{y}}{f_{0}} \times 100 \quad$ or $\quad \frac{\hat{f}_{x y}}{f_{0}} \times 100$

Histogram diagrams for every experiment showing the number of grid points per percentage change class in a limited area around La Palma and Tenerife (Fig. 4) were added to summarize this information. Maximum, minimum, mean $(\bar{x})$, standard deviation $(s)$ and skewness $\left(\gamma_{3}\right)$ values are shown in Table 4, where

$\bar{x}=\frac{1}{n} \sum_{i=1}^{n} x_{i}$

$s=\sqrt{\frac{1}{n} \sum_{i=1}^{n}\left(x_{i}-\bar{x}\right)^{2}} \quad$ and

$\gamma_{3}=\frac{\sum_{i=1}^{n}\left(x_{i}-\bar{x}\right)^{3} / n}{s^{3}}$

are the mathematical definition of the statistics, and $x_{1}, x_{2}, \cdots, x_{n}$ are the $n$ grid point values of percentage change used in their calculation.

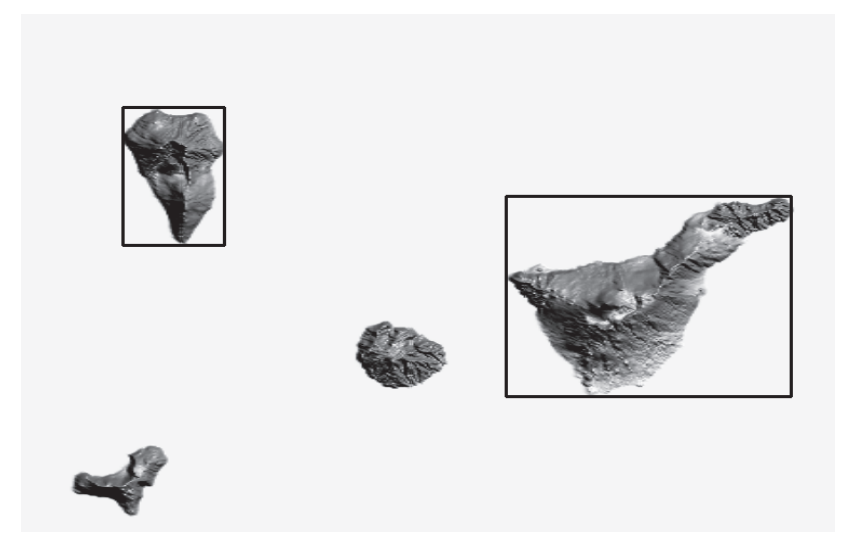

Figure 4. Areas of La Palma and Tenerife selected for statistical analysis.

Only the most relevant graphics and histograms are presented in Fig. 5 (ordered from a) to h) experiments 1, 6, 19, $24,21,20,11$ and 2). A shift to negative values are shown in figures a) to d). In contrast, positive increments in maximum velocities are presented in figures e) to $h$ ). 

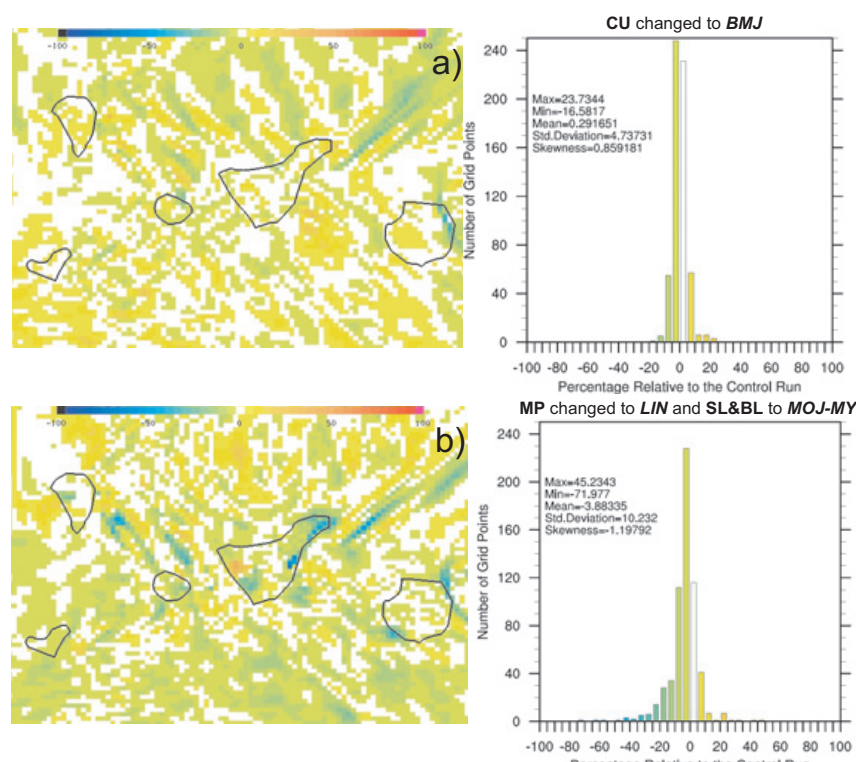

Percentage Relative to the Control
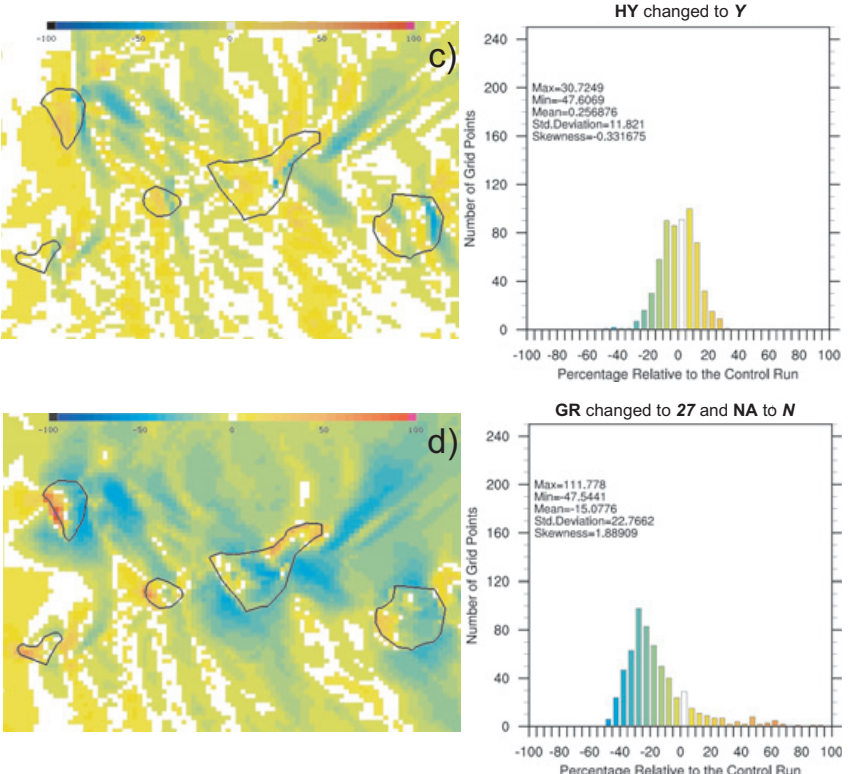
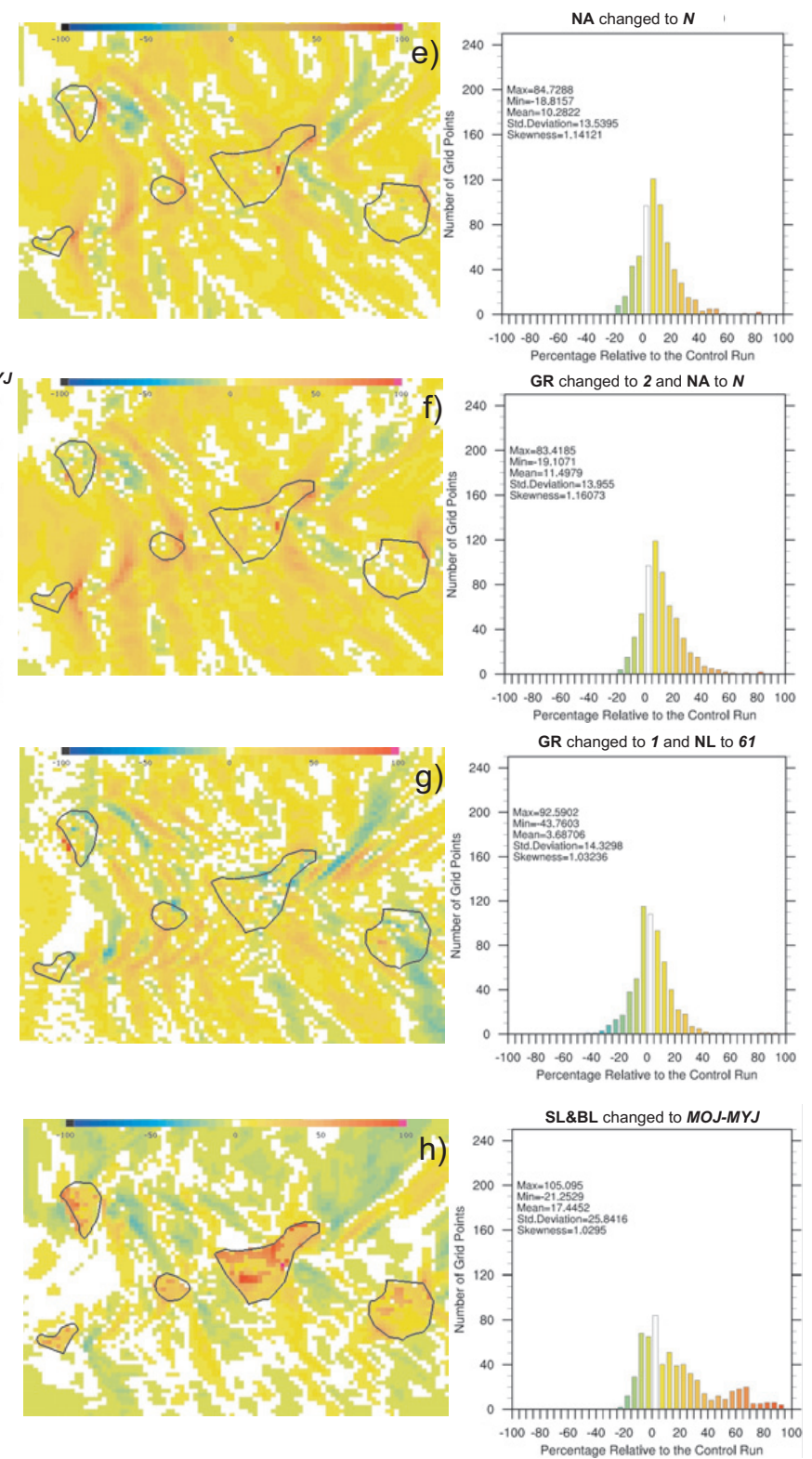

Figure 5. Percentage changes relatives to the Control Run Experiment. Histograms present data from La Palma and Tenerife areas and their statistics: maximum, minimum, mean $(x)$, standard deviation $(s)$ and skewness $\left(\gamma_{3}\right)$. Ordered from a) to h) experiments $1,6,19,24,21,20$, 11 and 2 are shown. The title of each histogram indicates the model options that were changed using the acronyms defined in Table 2.

\section{Discussion and conclusions}

The study of the results shows that most of the modifications of the model parameters had a moderate to strong impact in the $10 \mathrm{~m}$ maximum wind speed solution (see Table 4). The greatest positive variations were associated with modifications of the BL\&SL parameterization, increase in horizontal resolution and size domain diminishing without nesting. The largest negative changes were due to the nonlinear interaction between MP and BL\&SL in the case of L and MOJ-MYJ, de- crease in horizontal resolution and to the hydrostaticity activation. Neither increasing the number of levels to 41 or 61 nor changes in cumulus parameterization showed a significant variation. Size mother domain reduction, with twoway nesting grids activated, had a minor impact in the position of the storm modifying slightly the pattern of stagnation areas and the position of the maximum winds. The hydrostatic case showed a systematic diminishing of the maximum wind speed on the leeside locations. Symmetric histograms in experiments 4, 7 and 8 demonstrated an spatial shift in 
Table 4. Statistics of percentage changes (\%) relatives to the CRE associated to La Palma and Tenerife area values defined in Fig. 4. The $25 \%$ of the highest values are marked in red, and the $25 \%$ of the lowest in blue for every statistic.

\begin{tabular}{cccccc}
\hline Experiment & $\begin{array}{c}\text { Statistics } \\
\text { Max. }\end{array}$ & Min. & $\bar{x}$ & $s$ & $\gamma_{3}$ \\
\hline EXP.1 & 23.7 & -16.6 & 0.3 & 4.7 & 0.9 \\
EXP.2 & 105.1 & -21.3 & 17.4 & 25.8 & 1.0 \\
EXP.3 & 43.5 & -17.8 & 2.9 & 4.9 & 1.5 \\
EXP.4 & 31.5 & -44.3 & -4.4 & 8.9 & 0.0 \\
EXP.5 & 26.7 & -39.0 & -3.9 & 8.3 & -0.4 \\
EXP.6 & 45.2 & -72.0 & -3.8 & 10.2 & -1.2 \\
EXP.7 & 44.3 & -38.4 & 1.6 & 10.0 & -0.2 \\
EXP.8 & 28.2 & -39.2 & -0.4 & 5.4 & 0.2 \\
EXP.9 & 21.6 & -30.5 & -0.7 & 7.2 & -0.3 \\
EXP.10 & 39.0 & -15.9 & 3.3 & 6.6 & 0.9 \\
EXP.11 & 92.6 & -43.8 & 3.7 & 14.3 & 1.0 \\
EXP.12 & 41.3 & -12.9 & 1.9 & 5.9 & 1.8 \\
EXP.13 & 40.7 & -13.8 & 2.3 & 6.0 & 1.2 \\
EXP.14 & 83.6 & -34.2 & 1.2 & 10.4 & 4.9 \\
EXP.15 & 38.9 & -28.2 & 0.4 & 7.3 & 1.1 \\
EXP.16 & 60.2 & -38.0 & 2.2 & 10.0 & 0.9 \\
EXP.17 & 42.6 & -18.4 & 1.0 & 5.0 & 2.0 \\
EXP.18 & 41.8 & -22.6 & 1.1 & 7.7 & 0.4 \\
EXP.19 & 30.7 & -47.6 & 0.3 & 11.8 & -0.3 \\
EXP.20 & 83.4 & -19.1 & 11.5 & 14.0 & 1.2 \\
EXP.21 & 84.7 & -18.8 & 10.3 & 13.5 & 1.1 \\
EXP.22 & 50.6 & -37.2 & -2.4 & 14.0 & 0.6 \\
EXP.23 & 74.7 & -42.5 & -6.8 & 17.4 & 0.9 \\
EXP.24 & 111.8 & -47.5 & -15.1 & 22.8 & 1.9 \\
\hline & & & & & \\
\hline & & & & & \\
\hline
\end{tabular}

the positions of the wave pattern associated to the maximum winds. Percentage change graphics depict wavelike features associated to the capability of the model to reproduce the amplitude and spatial phase of the mountain wave structures. Strong hydraulic jumps on the leeside of Tenerife and $\mathrm{La}$ Palma are emphasized by some of the configurations (experiments 11,20 and 21) or minimized by others (experiments 22, 23, 24 and 19). These variations are related to resolution, nesting capability and hydrostaticity.

To conclude, taking into account that further meteorological cases should be simulated to confirm these results, it appears that if an ensemble for $10 \mathrm{~m}$ wind speed were to be designed, model runs with different BL\&SL schemes, horizontal resolutions, hydrostaticity options and nested grids activations should be included as an efficient way to increase the spread. Future work will focus on the use of these results to test an experimental ensemble system to forecast wind speeds at $10 \mathrm{~m}$.
Acknowledgements. The authors wish to thank Celia Milford and Juanjo de Bustos for their valuable contributions. The simulations were performed with the MareNostrum Supercomputer held by the Barcelona Supercomputing Center-Centro Nacional de Supercomputación. This work was funded by the Spanish Mobility Program ICTS of the Education and Science Ministry (Orden ECI/2136/2005, BOE de 5 de julio).

Edited by: F. Stel and D. B. Giaiotti

Reviewed by: three anonymous referees

\section{References}

Alpert, P. and Tsidulko, M.: Project Wind-numerical simulation with Tel Aviv Model PSU-NCAR model run at Tel Aviv University, Mesoscale Modeling of the Atmosphere, Meteor. Monogr, 47, 81-95, 1994.

Alpert, P., Stein, U., and Tsidulko, M.: Role of sea fluxes and topography in eastern Mediterranean cyclogenesis, The Global atmosphere and ocean system, 3, 55-79, 1995a.

Alpert, P., Tsidulko, M., and Stein, U.: Can Sensitivity Studies Yield Absolute Comparisons for the Effects of Several Processes?, J. Atmos. Sci., 52, 597-601, 1995b.

Alpert, P., Krichak, S., Krishnamurti, T., Stein, U., and Tsidulko, M.: The relative roles of lateral boundaries, initial conditions, and topography in mesoscale simulations of lee cyclogenesis, J. Appl. Meteorol., 35, 1091-1099, 1996a.

Alpert, P., Tsidulko, M., Krichak, S., and Stein, U.: A multi-stage evolution of an ALPEX cyclone, Tellus A, 48, 209-220, 1996b.

Berger, A.: 8 The Role of CO2, Sea Level, and Vegetation During the Milankovitch-Forced Glacial-Interglacial Cycles, Geosphere-Biosphere Interactions and Climate, p. 119, 2001.

Beven, J.: Tropical Cyclone Report on Tropical Strom Delta 22-28 November 2005, NOAA Tech. Note, Tropical Prediction Center, National Hurricane Center, http://www.tpc.ncep.noaa.gov/ pdf/TCR-AL292005_Delta.pdf, 2006.

Darby, L., Banta, R., and Pielke Sr, R.: Comparisons between mesoscale model terrain sensitivity studies and Doppler lidar measurements of the sea breeze at Monterey Bay, Mon. Weather Rev., 130, 2813-2838, 2002.

Draxler, R. and Rolph, G.: HYSPLIT (HYbrid Single-Particle Lagrangian Integrated Trajectory) Model access via NOAA ARL READY Website (http://www.arl.noaa.gov/ready/hysplit4.html), NOAA Air Resources Laboratory, Silver Spring, MD, 15, 2003.

Forbes, R. and Clark, P.: Sensitivity of extratropical cyclone mesoscale structure to the parametrization of ice microphysical processes, Q. J. Roy. Meteor. Soc., 129, 1123-1148, 2003.

Froude, L., Bengtsson, L., and Hodges, K.: The Predictability of Extratropical Storm Tracks and the Sensitivity of Their Prediction to the Observing System, Mon. Weather Rev., 135, 315-333, 2007.

Guan, S. and Reuter, G.: Numerical simulation of an industrial cumulus affected by heat, moisture, and $\mathrm{CCN}$ released from an oil refinery, J. Appl. Meteorol., 35, 1257-1264, 1996.

Jankov, I., Gallus Jr., W., Segal, M., Shaw, B., and Koch, S.: The Impact of Different WRF Model Physical Parameterizations and Their Interactions on Warm Season MCS Rainfall, Weather Forecast., 20, 1048-1060, 2005. 
Jorba, O., Marrero, C., Cuevas, E., and Baldasano, J.: Impact of the extratropical storm Delta over the Canary Islands on 28-30 November 2005: severe windstorm event, European Geosciences Union General Assembly 2007, Vienna, Austria, 15-20 April 2007, Geophys. Res. Abstr., 9, 07608, 2007.

Jorba, O., Marrero, C., Cuevas, E., and Baldasano, J. M.: High resolution modelling results of the wind flow over Canary Islands during the meteorological situation of the extratropical storm Delta (28-30 November 2005), Adv. Sci. Res., 2, 81-87, 2008.

Jung, T., Gulev, S., Rudeva, I., and Soloviov, V.: Sensitivity of extratropical cyclone characteristics to horizontal resolution in the ECMWF model, Geophys. Res. Abstr., 8, 03367, 2006.

Lynn, B., Stauffer, D., Wetzel, P., Tao, W., Alpert, P., Perlin, N., Baker, R., Muñoz, R., Boone, A., and Jia, Y.: Improved Simulation of Florida Summer Convection Using the PLACE Land Model and a 1.5-Order Turbulence Parameterization Coupled to the Penn State-NCAR Mesoscale Model, Mon. Weather Rev., 129, 1441-1461, 2001.

Marrero, C., Jorba, O., Cuevas, E., and Baldasano, J.: Extreme Wind Event over The Canary Islands Related to the Extratropical Storm Delta: Sensitivity Study with a Limited Area Model, XXIV International Union of Geodesy and Geophysics General Assembly 2007, Perugia, Italy, 2-13 July 2007, Poster Presentation MS013, proceedings page 5433, 2007.

Martín, F., Alejo, C., de Bustos, J., Calvo, F., San Ambrosio, I., Sánchez-Laulhé, J., and D., S.: Study of the tropical storm "Delta" and its extratropical transition: Meteorological impacts over Canary Islands (27-29 November 2005), Technical Report, Instituto Nacional de Meteorologa, http://www.inm.es/web/sup/ ciencia/divulga/nota_Delta/Delta.html, 2006.

McCaslin, P., Smart, J., Shaw, B., and Jamison, B.: A GRAPHICAL USER INTERFACE TO PREPARE THE STANDARD INITIALIZATION FOR WRF, 20th Conference on Weather Analysis and Forecasting/16th Conference on Numerical Weather Prediction, 84th AMS Annual Meeting, 11-15, 2004.
Michalakes, J., Dudhia, J., Gill, D., Henderson, T., Klemp, J., Skamarock, W., and Wang, W.: The Weather Research and Forecast Model: Software Architecture and Performance, Proceeding of the Eleventh ECMWF Workshop on the Use of High Performance Computing in Meteorology, 25-29, 2004.

NHC: 2005 Atlantic Hurricane Season, National Hurricane Center, http://www.nhc.noaa.gov/2005atlan.shtml, 2006.

Orlanski, I., Katzfey, J., Menendez, C., and Marino, M.: Simulation of an Extratropical Cyclone in the Southern Hemisphere: Model Sensitivity, J. Atmos. Sci., 48, 2293-2312, 1991.

Prater, B. and Evans, J.: Sensitivity of modeled tropical cyclone track and structure of hurricane Irene (1999) to the convective parameterization scheme, Meteorol. Atmos. Phys., 80, 103-115, 2002.

Ramis, C. and Romero, R.: A first numerical simulation of the development and structure of the sea breeze on the island of Mallorca, Annales Geophysicae, 13, 981-994, Springer, 1995.

Romero, R., Ramis, C., and Alonso, S.: Numerical simulation of an extreme rainfall event in Catalonia: Role of orography and evaporation from the sea, Q. J. Roy. Meteor. Soc., 123, 537-559, 1997.

Skamarock, W., Klemp, J., Dudhia, J., Gill, D., Barker, D., Wang, W., and Powers, J.: A Description of the Advanced Research WRF Version 2, NCAR Tech Notes-468+ STR, 2005.

Stein, U. and Alpert, P.: Factor Separation in Numerical Simulations, J. Atmos. Sci., 50, 2107-2115, 1993.

Warner, T., Peterson, R., and Treadon, R.: A tutorial on lateral boundary conditions as a basic and potentially serious limitation to regional numerical weather prediction, B. Am. Meteorol. Soc., 78, 2599-2617, 1997.

Zhu, H. and Thorpe, A.: Predictability of Extratropical Cyclones: The Influence of Initial Condition and Model Uncertainties, J. Atmos. Sci., 63, 1483-1497, 2006.

Zou, X., Kuo, Y., and Low-Nam, S.: Medium-Range Prediction of an Extratropical Oceanic Cyclone: Impact of Initial State, Mon. Weather Rev., 126, 2737-2763, 1998. 